\title{
EVALUACIÓN DEL ESPACIO VITAL DE CUYES CRIADOS EN POZAS
}

\author{
Fernando Cáceres O. ${ }^{1}$, Ronald Jiménez A. ${ }^{2}$, Miguel Ara G. ${ }^{3}$, Héctor Huamán U. ${ }^{4}$ \\ y Amparo Huamán C. ${ }^{2}$
}

\section{Abstract}

\begin{abstract}
The effect of vital area on productive and reproductive performance was evaluated in 2,325 guinea pigs at IVITA El Mantaro Research Station (300 growing male and female guinea pigs, 750 fattening male and female guinea pigs and 200 female and 25 first mating male guinea pigs). The study was divided in seven assays. Five different vital areas and five different number of animals per well were evaluated in each assay. A total of 25 wells were used for each assay. Different variables (body weight gain, alfalfa intake, feeding convertion index, number of scars due to fights, litter size, mortality and profit/cost index) associated to each productive phase were analyzed. Larger vital areas in assays that involved growing and fattening males resulted in greater body weight gain, lower alfalfa intake, lower feeding convertion index and lower number of scars due to fights. All of these variables showed significant lineal response patterns $(p=0.0001$ to 0.02 for growing males and $\mathrm{p}=0.0001$ to 0.0007 in fattening males). The same pattern was shown for growing females except for body weight gain. For fattening females, weight gain and profit/cost index were adjusted to cuadratic regresion reaching a biological and an economic optimum at 0.19 and $0.18 \mathrm{~m}$ /guinea pig. The following vital areas were recommended: $0.16 \mathrm{~m}^{2} /$ guinea pig for growing males, $0.14 \mathrm{~m}^{2} /$ guinea pig for growing females, $0.24 \mathrm{~m}^{2} /$ guinea pig for fattening males, $0.18 \mathrm{~m}^{2} /$ guinea pig for fattening females, and $0.28 \mathrm{~m}^{2} /$ guinea pig for breeding animals.
\end{abstract}

Key words: Peru, guinea pigs, vital area, productive performance, reproductive performance

\section{Resumien}

El efecto del espacio vital sobre los parámetros productivos y reproductivos fue evaluado en 2,325 cuyes de la Estación IVITA El Mantaro (300 machos y hembras de recría, 750 machos y hembras de engorde y 200 hembras y 25 machos de primer empadre). El estudio se dividió en siete ensayos evaluando en cada uno de ellos cinco diferentes espacios vitales con cinco diferentes cantidades de animales por poza, totalizando 25 pozas para cada ensayo. Se analizaron variables asociadas a cada etapa productiva (ganancia de peso, consumo de alfalfa, índice de conversión alimenticia, número de cicatrices debido a peleas, tamaño de camada, mortalidad y la relación beneficio/costo). En los ensayos de recría y engorde de machos los mayores espacios vitales permitieron

\footnotetext{
${ }^{1}$ Práctica privada

${ }^{2}$ Estación Experimental del Centro de Investigaciones IVITA-El Mantaro, FMV-UNMSM

${ }^{3}$ Centro de Investigaciones IVITA, FMV-UNMSM

${ }^{4}$ Laboratorio de Bioquímica, Nutrición y Alimentación, FMV-UNMSM
} 


\begin{abstract}
obtener mayores ganancias de peso, menor consumo de alfalfa, menor índice de conversión alimenticia y menor número de cicatrices por animal, presentando patrones de respuesta lineal significativos $(p=0.0001$ a 0.02 en recría de machos y $p=0.0001$ a 0.0007 en engorde de machos). En las hembras de recría se obtuvieron los mismos patrones excepto en la ganancia de peso. En las hembras de engorde la ganancia de peso y el índice beneficio/costo se ajustaron a regresiones cuadráticas alcanzando un óptimo biológico y económico a 0.19 y $0.18 \mathrm{~m}^{2} / \mathrm{cuy}$, respectivamente. Se recomiendan los siguientes espacios vitales: $0.16 \mathrm{~m}^{2} /$ cuy para machos de recría, $0.14 \mathrm{~m}^{2} /$ cuy para hembras de recria, 0.24 $\mathrm{m}^{2} /$ cuy para machos de engorde, $0.18 \mathrm{~m}^{2} /$ cuy para hembras de engorde y $0.28 \mathrm{~m}^{2} /$ cuy para pozas de reproducción.
\end{abstract}

Palabras clave: Perú, cuy, espacio vital, parámetro productivo, parámetro reproductivo

\section{INTRODUCCIÓN}

El incremento en la demanda de proteína animal para la alimentación humana ha ocasionado ciertos cambios en los sistemas de producción ganadera intensiva con el fin de obtener la mayor cantidad de proteína en el menor tiempo posible (Denaburski et al., 2003). Tales cambios se han dado fundamentalmente en el entorno o medio ambiente que rodea a los animales, el cual influye en su comportamiento productivo (Carpenter, 1995). Dentro de estos factores ambientales se encuentra el espacio vital, el cual juega un rol importante en los aspectos de estrés. En el cuy, el espacio vital reducido le genera incomodidad para alimentarse, desplazarse, descansar, etc., afectando sus niveles productivos y reproductivos. Los estudios realizados para determinar requerimientos de espacio vital en cuyes se remontan a la década de los setenta (Humala, 1971; Agustín, 1973); sin embargo, las prácticas de selección y mejoramiento genético han hecho posible que, en la actualidad, los cuyes sean de mayor tamaño y peso, lo que hace lógico deducir que los requerimientos de espacio vital han variado.

En el valle del Mantaro se tiene unos 80 medianos productores con poblaciones entre 20 a 80 cuyes madres cada uno y 12 grandes productores con poblaciones mayores a 100 cuyes madres cada uno. La mayoría de los productores cría cuyes mejorados o sus cru- ces; albergados en pozas construidas con materiales locales, con densidades aproximadas de $0.12 \mathrm{~m}^{2}$ por cuy.

Basándose en estos antecedentes el presente estudio tuvo por finalidad evaluar el efecto del espacio vital sobre los parámetros productivos, reproductivos y económicos de cada fase de la crianza comercial de cuyes en el valle del Mantaro, a fin de recomendar espacios vitales que proporcionen mayores beneficios a los productores.

\section{Materiales y Métodos}

\section{Ubicación}

El estudio se realizó entre octubre 2002 y junio 2003 en la Estación Experimental del Instituto Veterinario de Investigaciones Tropicales y de Altura (IVITA), ubicada en el km 34 de la carretera Huancayo-Jauja, distrito de El Mantaro, departamento de Junín, a una altitud de 3,320 msnm. La zona tiene una temperatura promedio anual de $12{ }^{\circ} \mathrm{C}$ y una precipitación pluvial promedio anual de 770 $\mathrm{mm}$.

\section{Animales}

Se emplearon 2,325 cuyes (1,250 hembras y 1,075 machos) además de los gazapos nacidos durante la ejecución del ensayo de maternidad. Fueron utilizados cuyes de los 
Cuadro 1. Tratamientos y bloques empleados en la evaluación del espacio vital de cuyes criados en pozas

\begin{tabular}{|c|c|c|c|c|c|c|c|c|c|c|c|}
\hline \multirow{2}{*}{$\begin{array}{c}\text { Ensayo } \\
1 \text { y } 2\end{array}$} & \multicolumn{5}{|c|}{$\begin{array}{l}\text { Espacio vital }{ }^{1} \\
\left(\mathrm{~m}^{2} / \text { cuy }\right)\end{array}$} & \multicolumn{5}{|c|}{$\begin{array}{l}\text { Animales por poza } \\
\text { (n) }\end{array}$} & \multirow{2}{*}{$\begin{array}{c}\text { Pozas } \\
\text { (n) }\end{array}$} \\
\hline & 0.10 & 0.12 & 0.14 & 0.16 & 0.18 & 4 & 8 & 12 & 16 & 20 & \\
\hline 3 & 0.16 & 0.20 & 0.24 & 0.28 & 0.32 & 5 & 7 & 9 & 11 & 13 & 25 \\
\hline 4 & 0.16 & 0.20 & 0.24 & 0.28 & 0.32 & 4 & 6 & 8 & 10 & 12 & 25 \\
\hline 5 & 0.16 & 0.20 & 0.24 & 0.28 & 0.32 & 4 & 6 & 8 & 10 & 12 & 25 \\
\hline 6 y 7 & 0.08 & 0.12 & 0.16 & 0.20 & 0.24 & 10 & 20 & 30 & 40 & 50 & 25 \\
\hline
\end{tabular}

${ }^{1}$ Las pozas empleadas en los ensayos 1 a 5 y en los ensayos 6 y 7 tenían un ancho de 1.5 y $2.0 \mathrm{~m}$, respectivamente. El otro lado era movible y permitía ajustar el espacio vital requerido para cada poza.

tipos I (cuyes de pelo corto y lacio), III (cuyes de pelo largo) y IV (cuyes de pelo erizado), los cuales fueron distribuidos en pozas en forma estratificada y al azar (95\% del tipo I, 3\% del tipo IV y $2 \%$ del tipo III). Los cuyes fueron de una línea mejorada por el IVITA, que se encuentra adaptada a la zona y se caracteriza por tener una buena ganancia de peso y una adecuada conformación corporal. Se utilizó alfalfa verde, de la variedad Suprema, para suministrar a los animales una ración diaria equivalente a 400 gramos de alfalfa verde por $\mathrm{kg}$ de peso vivo.

\section{Ensayos y tratamientos}

Se realizaron siete ensayos, correspondientes a las diferentes etapas productivas que conforman la crianza de cuyes en pozas en el valle del Mantaro, a fin de evaluar el efecto del espacio vital sobre la crianza del cuy.

? Ensayos 1 y 2 (machos y hembras en recría, respectivamente). Se evaluó desde los 15 hasta los 45 días de edad.

? Ensayo 3 (empadre). Se seleccionaron hembras y machos primerizos. Las hembras de tres meses de edad y $900 \mathrm{~g}$ de peso vivo y los machos de seis meses de edad y 1,800 g de peso vivo. En cada grupo de hembras se colocó un macho durante 25 días.

? Ensayo 4 (preñez). Se usaron las hembras empadradas en el ensayo 3, durante 60 días, aproximadamente.

? Ensayo 5 (maternidad). Se usaron las hembras preñadas del ensayo 4 , quienes parieron y estuvieron junto a sus crías, hasta los 15 días de lactación.

? Ensayos 6 y 7 (engorde de machos y hembras, respectivamente). Se emplearon cuyes de 45 días de edad promedio, por un periodo de 45 días.

Los espacios vitales (tratamientos) así como los números de animales por poza (bloques) para cada ensayo se muestran en el Cuadro 1.

Se determinó la ganancia de peso, el consumo de alfalfa, el índice de conversión alimenticia, el número de cicatrices debido a peleas, la fertilidad, el tamaño de camada, la mortalidad y la relación beneficio-costo.

\section{Diseño experimental}

La información obtenida para cada variable en cada ensayo fue sometida a un aná- 
lisis de varianza para un diseño de bloques completos al azar con cinco tratamientos (espacio vital) y cinco bloques (número de animales por poza), así como a un análisis de regresión de la variable de respuesta sobre el espacio vital.

Los datos de conteo de cicatrices fueron transformados a su raíz cuadrada para aproximar la asunción de normalidad del análisis de varianza y del análisis de regresión (Snedecor y Cochran, 1967). A su vez, los datos de mortalidad y de fertilidad fueron evaluados mediante tablas de contingencia usando la prueba de chi-cuadrado, bajo una hipótesis nula de igualdad de efectos entre tratamientos.

La relación beneficio-costo se obtuvo para cada una de las pozas de los ensayos de crecimiento (1 y 2 ), engorde $(6,7)$ y de la etapa reproductiva $(3,4$ y 5$)$. En base al espacio vital ofrecido y el número de unidades animales para cada etapa productiva se obtuvo el espacio requerido en pozas y por consiguiente el área total del galpón a utilizar, determinándose así los costos de construcción de instalaciones y el resto de costos fijos, directos e indirectos, los cuales sumados representan el total de costos anuales para cada poza. Para determinar los ingresos anuales para la misma poza, en base a los datos de las variables antes mencionadas, se obtuvo la producción anual expresada en unidades y en $\mathrm{kg}$ de cuy que multiplicada por el precio de venta dio como resultado los ingresos anuales. El análisis de la relación beneficiocosto permitió recomendar espacios vitales para cada uno de los ensayos.

\section{Resultados y Discusión}

\section{Etapa de recría}

La Fig. 1 muestra el comportamiento de las variables evaluadas en el ensayo de recría de machos (ensayos 1 y 2). La ganancia de peso (Fig. 1a) registró un patrón lineal de respuesta estadísticamente significativo al espacio vital $(p=0.0169)$. Esta misma respuesta lineal, pero negativa, se observó en el consumo de alfalfa (Fig. 1b) $(p=0.02)$, en el índice de conversión alimenticia (Fig. 1c) ( $\mathrm{p}=0.0006)$ y en el número de cicatrices (Fig. 1d) $(p=0.0001)$. Los coeficientes de determinación sugieren que la mayor parte de la variación en las respuestas es explicada por el incremento en el espacio vital (Fig. 1).

En hembras se obtuvieron las mismas tendencias (Fig. 2), a excepción de la ganancia de peso, la cual no presentó un patrón de respuesta estadísticamente significativo (Fig. 2a).

El efecto favorable de un mayor espacio vital sobre la ganancia de peso en cuyes fue experimentado por Humala (1971) y Agustín (1973), pero también se demostró en pollos (Quiñones et al., 1986 a,b; Llorente et al., 1986; Polanco y Manso, 1986) y cerdos (Díaz et al., 2002).

El insuficiente espacio vital estresa a los animales y hace que se incremente la frecuencia de peleas. Este comportamiento agresivo se ve reflejado en los datos de cicatrices dorsales (Figs. 1d y 2d), notándose la tendencia lineal decreciente al aumentar el espacio vital.

La variación en espacios vitales usada en la etapa de crecimiento no afectó significativamente la mortalidad en las pozas. Es evidente la ausencia de ajuste a una función cuadrática de la mayoría de variables de respuesta en machos y hembras. La ausencia de un punto de inflexión en el patrón de respuesta es generalmente explicada por la presencia de terceros factores severamente limitantes o debido un rango demasiado estrecho de niveles experimentales. En los ensayos de recría, tanto las ganancias de peso obtenidas en machos en cada uno de los niveles (240 a $283 \mathrm{~g}$ ) y en hembras (201 a 236 g) fueron satisfactorias (Chauca, 1997), por lo tanto es posible que se haya usado un rango insuficiente de espacios vitales. 

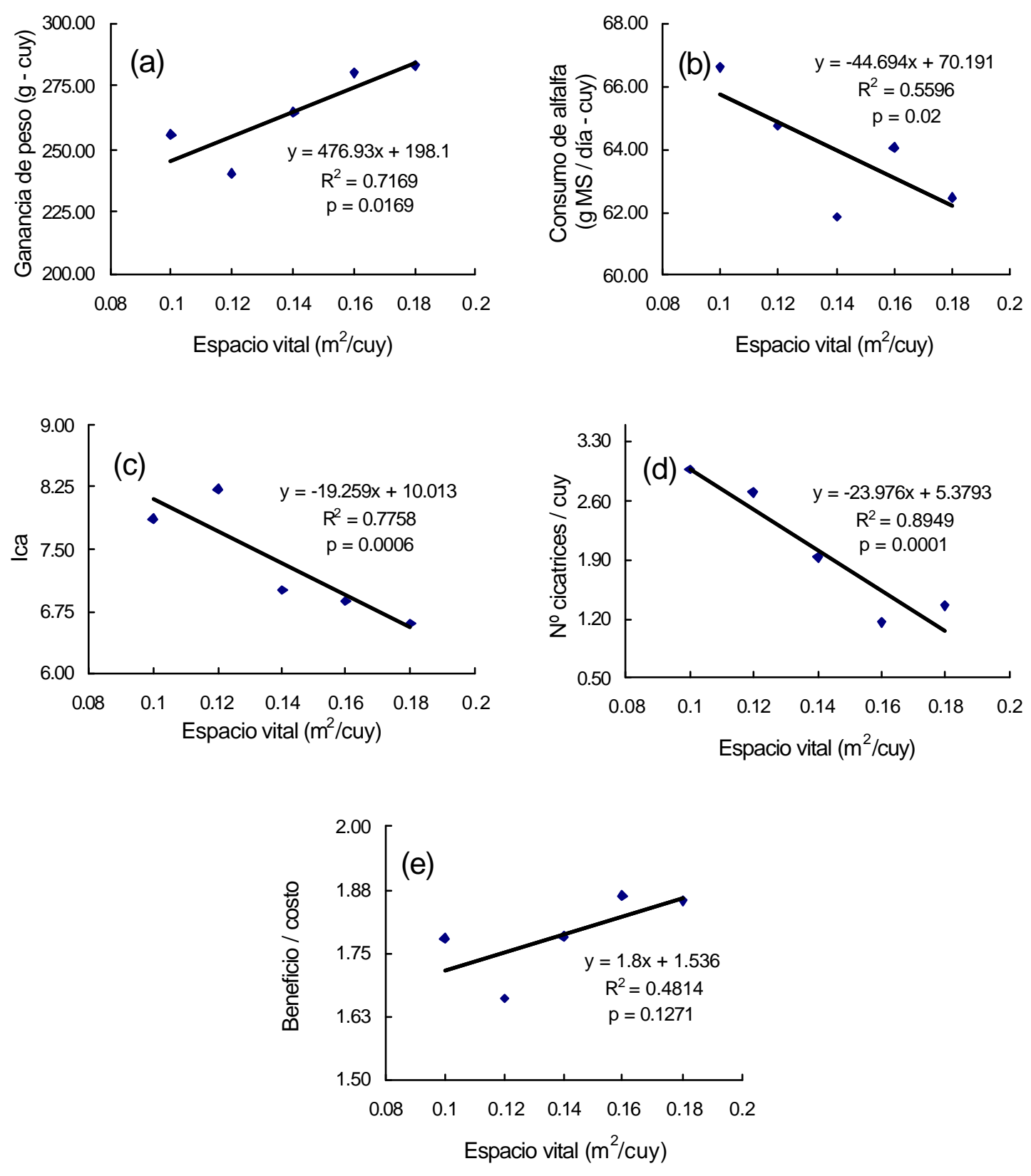

Figura 1. Relación entre el espacio vital en cuyes criados en pozas ( $\mathrm{m}^{2} / \mathrm{cuy}$ ) y las variables productivas de respuesta (a) ganancia de peso, b) consumo de alfalfa, c) índice de conversión alimenticia, d) № de cicatrices por cuy, e) beneficio/costo] en machos de recría (15 a 45 días de edad) 

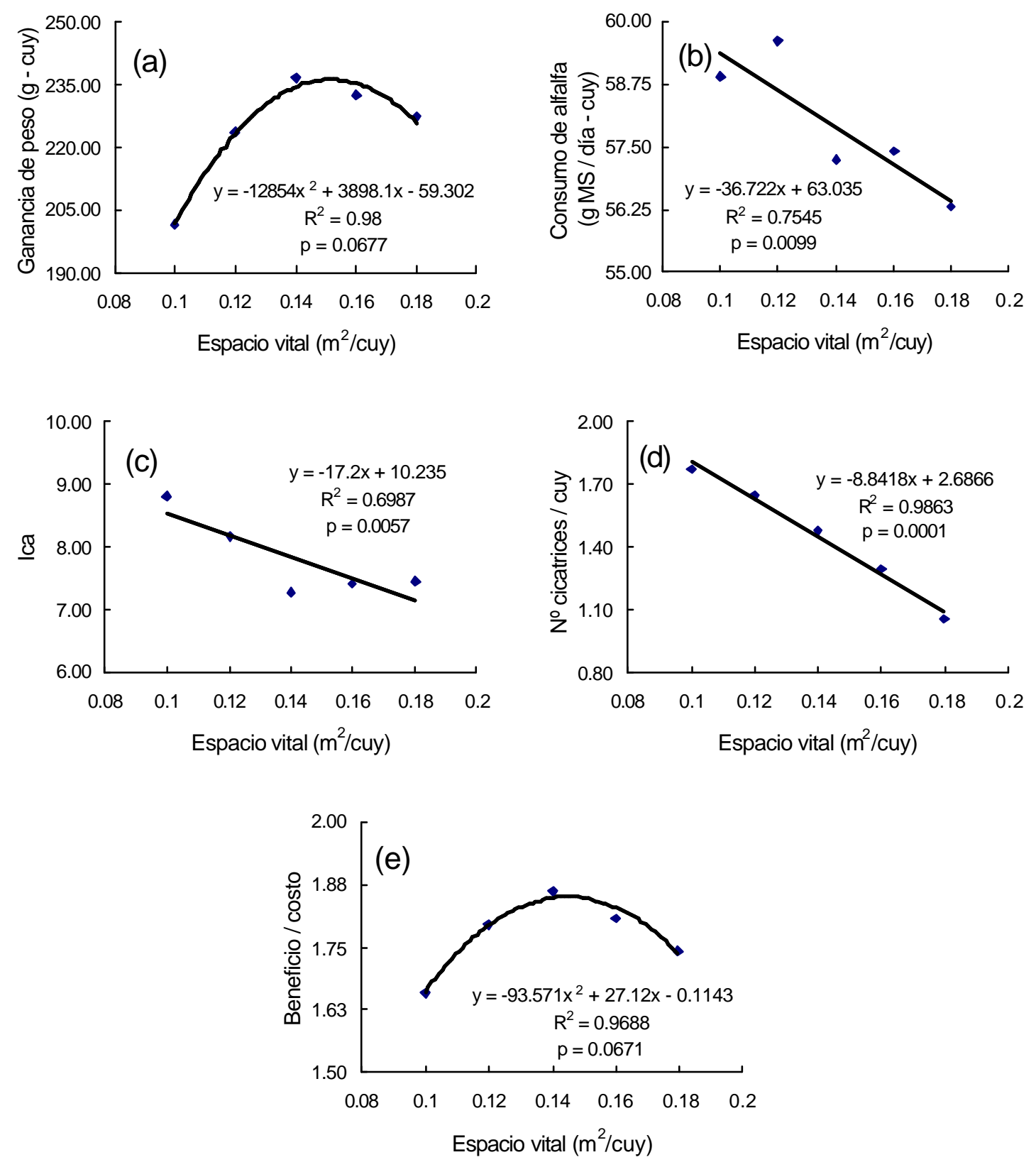

Figura 2. Relación entre el espacio vital en cuyes criados en pozas ( $\mathrm{m}^{2} / \mathrm{cuy}$ ) y las variables productivas de respuesta [a) ganancia de peso, b) consumo de alfalfa, c) índice de conversión alimenticia, d) № de cicatrices por cuy, e) beneficio/costo)] en hembras de recría (15 a 45 días de edad) 

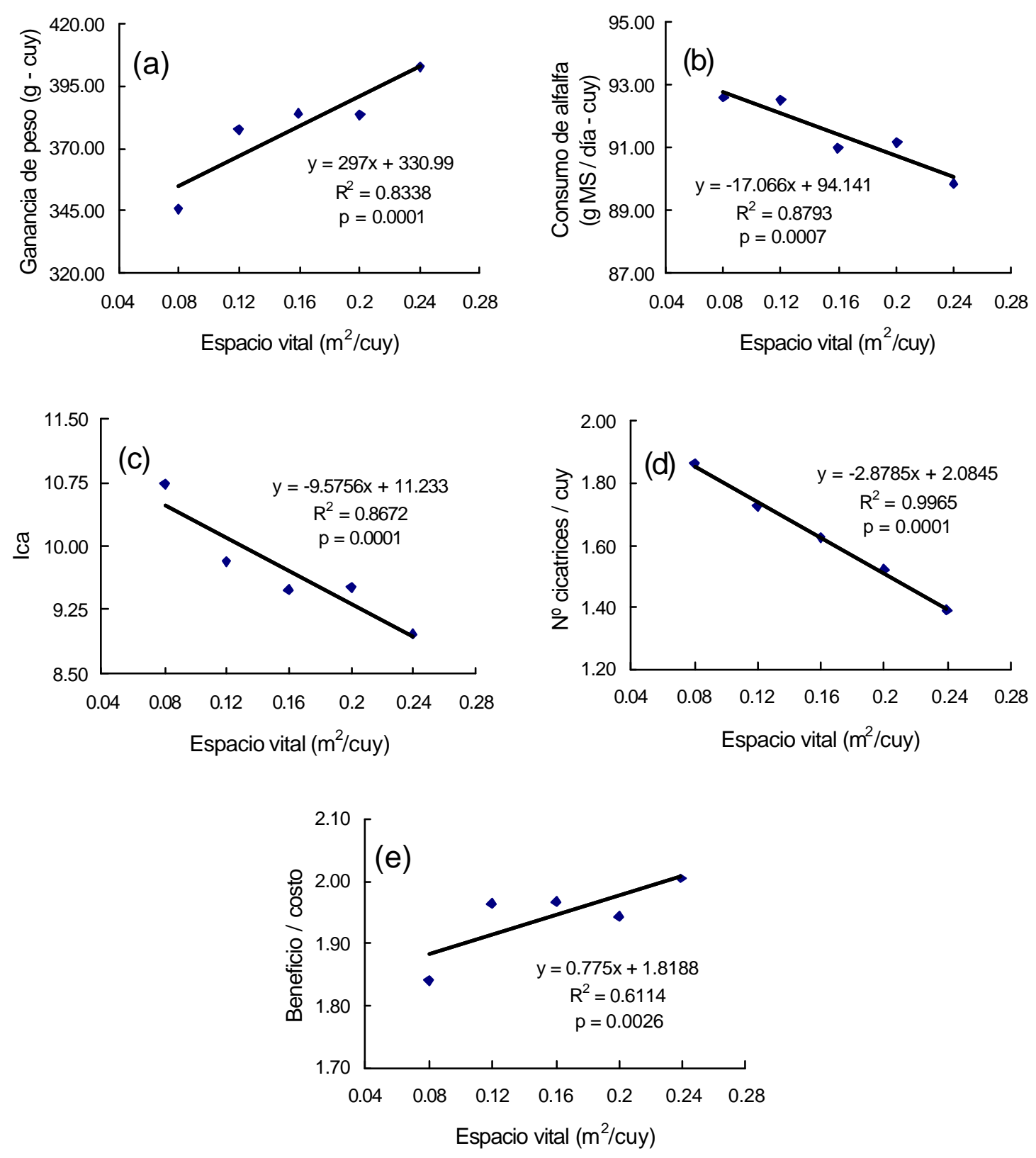

Figura 3. Relación entre el espacio vital en cuyes criados en pozas ( $\left.\mathrm{m}^{2} / \mathrm{cuy}\right)$ y las variables productivas de respuesta (a) ganancia de peso, b) consumo de alfalfa, c) índice de conversión alimenticia, d) № de cicatrices/cuy, e) Relación beneficio/costo] en machos de engorde 
Sin duda, la variable que determina la elección de un espacio vital óptimo es la relación beneficio-costo. Si bien a mayores espacios vitales se elevan los costos de instalaciones, se pueden obtener ventajas en términos de ganancia de peso e índice de conversión alimenticia. Al observar las tendencias mostradas en la Fig. 1e, resulta recomendable usar $0.16 \mathrm{~m}^{2} /$ cuy para la etapa de recría de machos, debido al mayor índice beneficio-costo. Similarmente, se recomienda alojar a las hembras en pozas de $0.14 \mathrm{~m}^{2} /$ cuy (Fig. 2e).

\section{Etapa de engorde}

En el ensayo 6 de engorde de machos, todas las variables de respuesta observadas, a excepción de la mortalidad, mostraron patrones lineales de incremento (ganancia de peso, beneficio-costo) o de decrecimiento (consumo de alfalfa, índice de conversión alimenticia y número de cicatrices) estadísticamente significativos $(\mathrm{p}=0.0001 \mathrm{a}$ 0.0026 ) al variar el espacio vital (Fig. 3). Los coeficientes de determinación, tal como ocurrió en los ensayos de recría, hacen suponer que la mayor variación en las respuestas sería a consecuencia de los incrementos en espacio vital.

Los resultados fueron similares en hembras, excepto que los patrones de respuesta en ganancia de peso y beneficio-costo se ajustaron mejor a una función cuadrática (Fig. $4 a, e)$.

Se observó un mayor incremento de peso en machos que en hembras y la tendencia a ganar más peso a medida que el espacio vital aumenta coincide con los estudios realizados por Agustín (1973) y Humala (1971) en cuyes.

Es notoria la falta de ajuste a funciones cuadráticas en las respuestas de todas las variables evaluadas en machos (Fig. 3). Sin embargo, las ganancias de peso alcanzadas (entre 346 y $402 \mathrm{~g}$ ) permitieron alcanzar un peso de comercialización superior a los $900 \mathrm{~g}$ recomendados por Chauca (1997), lo cual sugiere que no se empleó un rango suficiente de espacios vitales. Dado que las respuestas han sido estadísticamente significativas, se debe recomendar los niveles más altos de espacio vital $\left(0.24 \mathrm{~m}^{2} /\right.$ cuy $)$ debido al mayor índice beneficio-costo alcanzado. En hembras, por el contrario, los espacios vitales óptimos a partir de las funciones de respuesta obtenidas en ganancia de peso y beneficio-costo son de 0.19 y $0.18 \mathrm{~m}^{2} /$ cuy.

No existieron diferencias significativas para mortalidad en los ensayos 6 y 7. Sin embargo, la cantidad de cicatrices en el dorso, producto de las peleas, manifestó la misma tendencia descendente descrita en los ensayos de recría; donde los cuyes en pozas con menor espacio vital presentaron el mayor número de cicatrices, disminuyendo el mérito de las carcasas.

\section{Etapa reproductiva}

La Fig. 5 muestra el comportamiento de las variables durante el empadre. La variación de peso en las hembras (Fig. 5a) no mostró un patrón de respuesta estadísticamente significativo, alcanzando su máximo nivel a $0.24 \mathrm{~m}^{2} /$ cuy (117 g), en contraposición a los machos ubicados en este mismo espacio vital, quienes manifestaron la mayor pérdida de peso (220 g) (Fig. 5b).

En el caso del consumo de alfalfa se muestra la tendencia lineal a decrecer a medida que aumenta el espacio vital, tanto en el empadre (Fig. 5c) como en la preñez (Fig. 6b), ajustándose a una regresión cuadrática. Los patrones de respuesta lineales significativos de las Figs. 5d, 5e y $6 \mathrm{c}$ evidencian que durante el empadre y la preñez, el número de cicatrices más alto se presentó en los espacios vitales más reducidos, lo cual sugiere que esta variable sería un indicador preciso del estrés experimentado por los animales sometidos a altas densidades.

El mayor incremento de peso en el ensayo de preñez (Fig. 6a) se alcanzó a 0.28 $\mathrm{m}^{2} /$ cuy, siendo este mismo espacio el que 

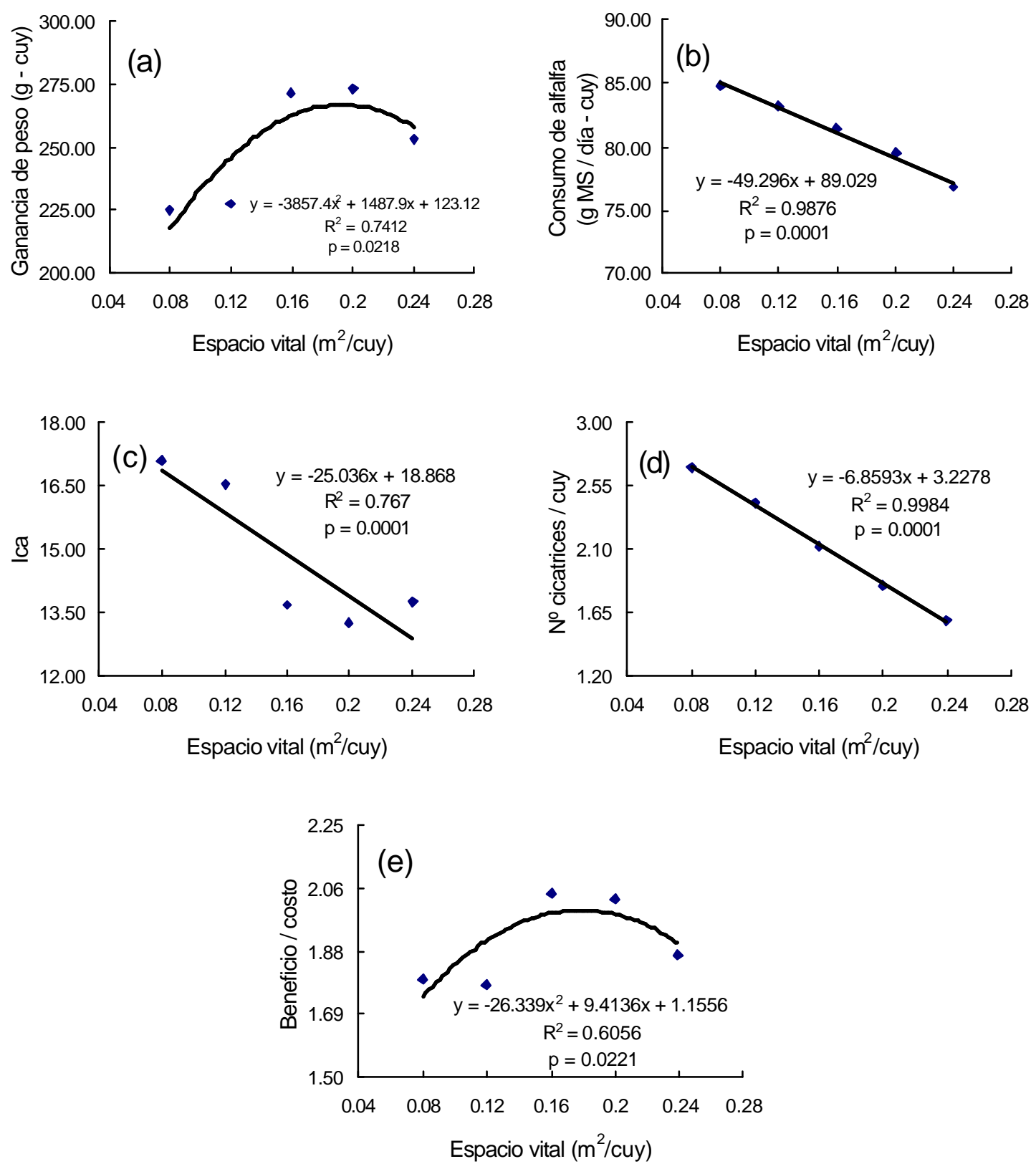

Figura 4. Relación entre el espacio vital en cuyes criados en pozas $\left(\mathrm{m}^{2} / \mathrm{cuy}\right)$ y las variables productivas de respuesta (a) ganancia de peso, b) consumo de alfalfa, c) índice de conversión alimenticia, d) № de cicatrices/cuy, e) Relación beneficio/costo] en hembras de engorde 

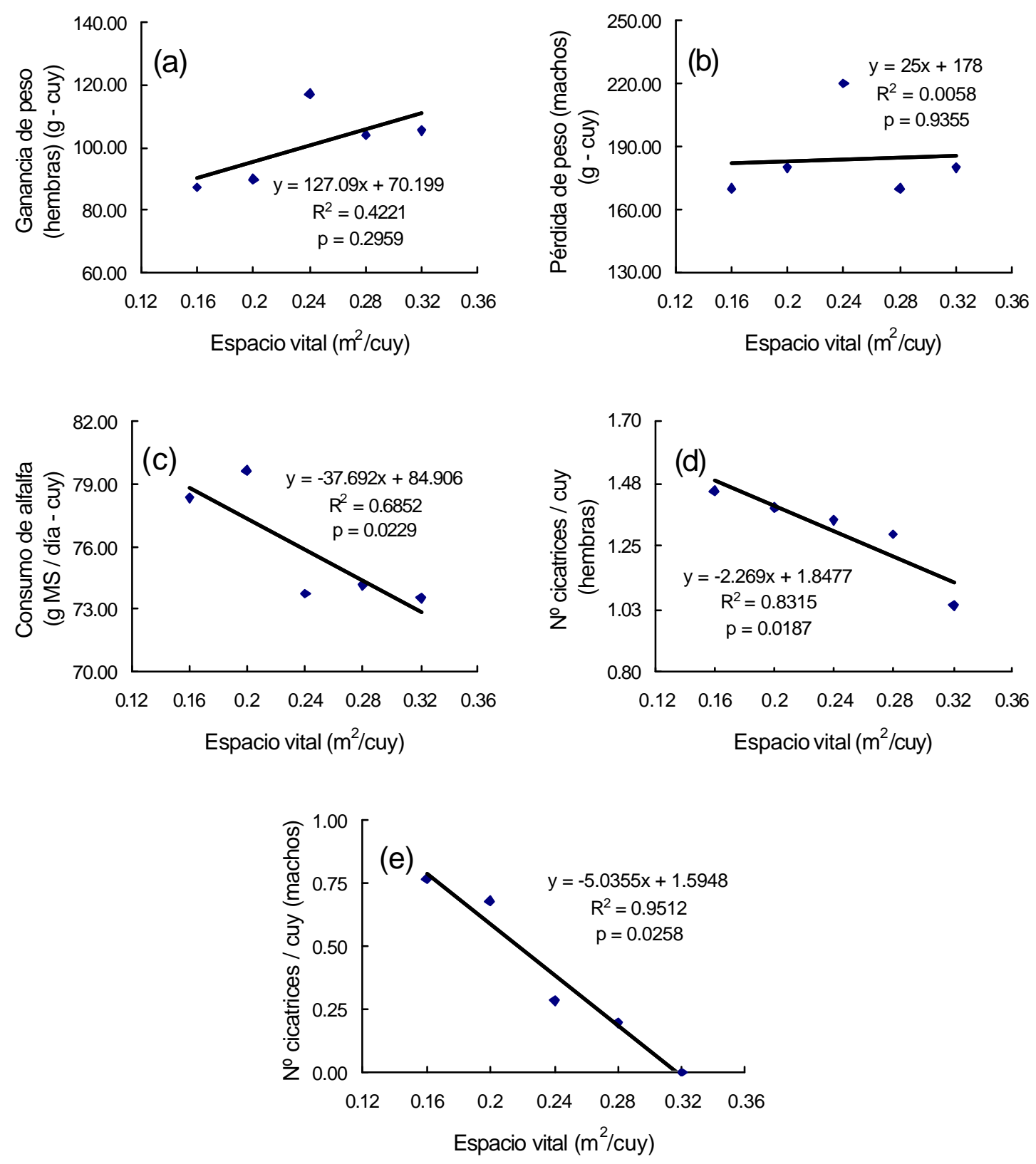

Figura 5. Relación entre el espacio vital en cuyes criados en pozas ( $\mathrm{m}^{2} / \mathrm{cuy}$ ) y las variables productivas de respuesta [(a) ganancia de peso en hembras, b) pérdida de peso en machos, c) consumo de alfalfa, d) № de cicatrices/cuy hembra, e) № de cicatrices/cuy macho] durante el empadre 

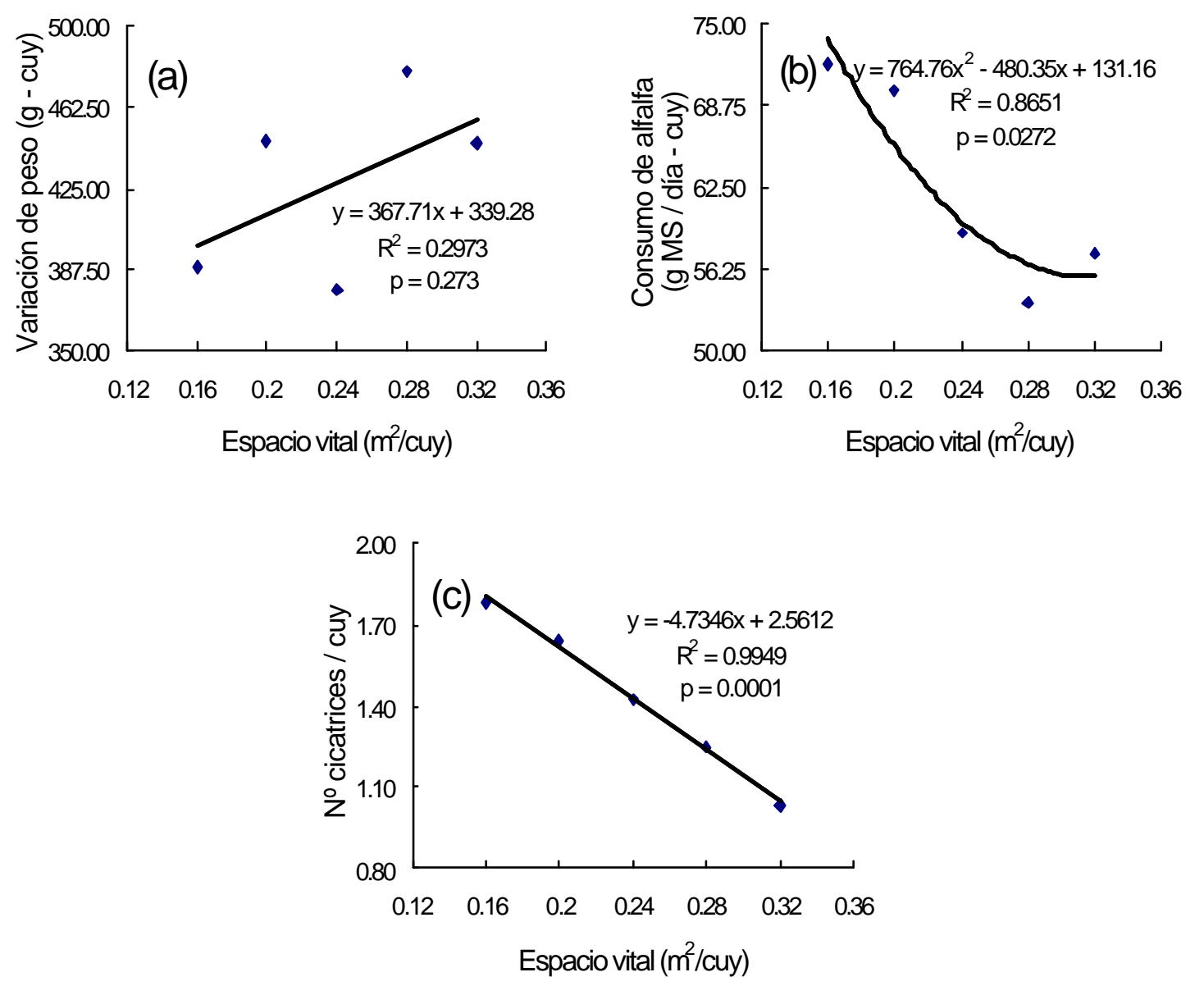

Figura 6. Relación entre el espacio vital en cuyes criados en pozas ( $\mathrm{m}^{2} / \mathrm{cuy}$ ) y las variables productivas de respuesta [(a) variación de peso, b) consumo de alfalfa, c) № de cicatrices/cuy] durante la preñez

permitió lograr los mayores tamaños de camada (3.06) tal como se observa en la Fig. 7a. Sin embargo, ambas variables no mostraron un patrón de respuesta significativo.

De las figuras $7 \mathrm{~b}$ y $7 \mathrm{c}$ es posible resaltar la tendencia estadísticamente significativa de las madres y las crías a ganar más peso en los mayores espacios vitales (83 y $273 \mathrm{~g}$, respectivamente), aunque el consumo de alfalfa en estas pozas se ve incrementado (Fig. 7d) debido al mayor número de crías. El nú- mero de cicatrices, al igual que en todos los ensayos, disminuye a medida que los animales reciben mayor espacio vital (Figs.7e y 7f).

No se registró diferencia estadística significativa por mortalidad en ninguno de los ensayos que integraron la etapa reproductiva. Estos datos, favorables para las menores densidades en reproducción, concuerdan con estudios similares realizados en Lambayeque por Coyotupa et al. (1994) y el realizado por INIAA-CIID (1990). El análisis de benefi- 

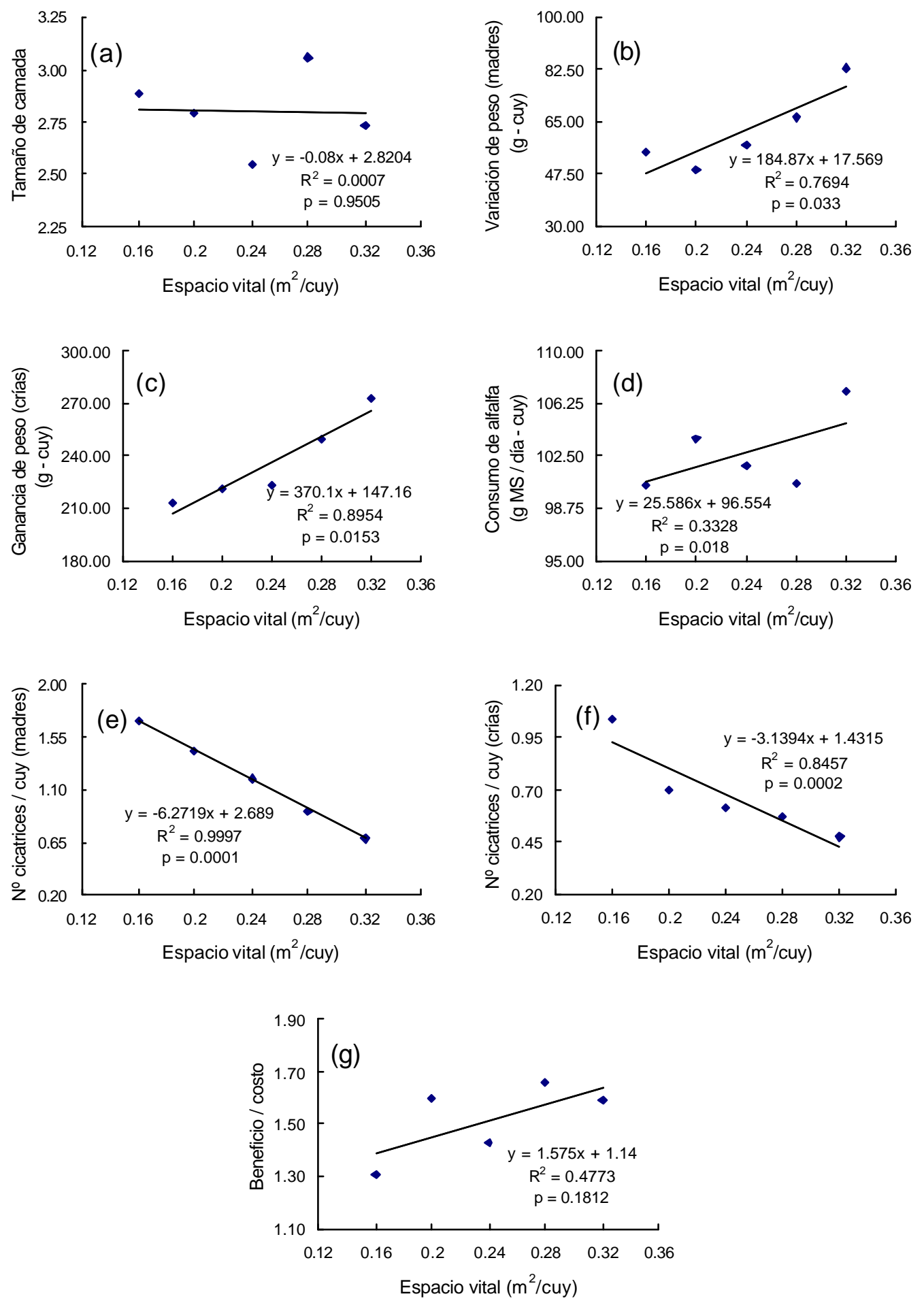

Figura 7. Relación entre el espacio vital en cuyes criados en pozas $\left(\mathrm{m}^{2} / \mathrm{cuy}\right)$ y las variables productivas de respuesta [(a) tamaño de camada, b) variación de peso de las madres, c) ganancia de peso de las crías, d) consumo de alfalfa, e) $\mathrm{N}^{\circ}$ de cicatrices en las madres, f) número de cicatrices en las crías, g) Relación beneficio/costo] durante la maternidad 
cio-costo integró toda la etapa reproductiva (Fig. 7g), observándose el mayor índice cuando se emplea $0.28 \mathrm{~m}^{2} /$ cuy.

\section{Conclusiones}

? La mayor rentabilidad expresada por el mayor índice beneficio-costo para machos de recría se alcanzó en las pozas con $0.16 \mathrm{~m}^{2} / \mathrm{cuy}$ y para hembras de recría en las pozas con $0.14 \mathrm{~m}^{2} /$ cuy .

? La respuesta de las variables integradas en el índice beneficiocosto alcanzó su mayor valor al emplear $0.24 \mathrm{~m}^{2} /$ cuy macho y 0.18 $\mathrm{m}^{2} /$ cuy hembra en las pozas de engorde.

? Al integrar los ensayos de empadre, preñez y maternidad se obtuvo la mayor rentabilidad al emplear pozas con $0.28 \mathrm{~m}^{2} /$ cuy.

? Las tendencias encontradas en las variables fueron mayoritariamente lineales, lo cual sugiere que los rangos de espacios vitales deben ser ampliados en una futura investigación.

\section{Limeratura Citada}

1. Agustín, R. 1973. Efecto del área y densidad de crianza en el engorde de cuyes (4 a 13 semanas de edad). Tesis de Bachiller. Facultad de Zootecnia, Univ. Nacional Agraria La Molina. Lima.

2. Carpenter, J. 1995. La complejidad del ambiente de un animal y los factores estresantes. Tecnología Avipecuaria 8: 41-43.

3. Chauca, L. 1997. Producción de cuyes (Cavia porcellus). p 1-12. FAO. Roma, Italia.
4. Coyotupa, J.; G. Vassallo; B. Aguinaga. 1994. Rendimiento reproductivo y productivo en cuyes de acuerdo con la densidad por poza. En: Investigación en cuyes. p 87. INIA. Lima.

5. Denaburski, J.; F. Siaz; T. Bak. 2003. Efecto desfavorable del estrés en la producción intensiva del ganado. Disponible: http://www.ucm.es/cgi-bin/s?c compludoc030310\&claves $=\mathrm{AU} \% 3 \mathrm{~d} \% 28 \% 27$ DenaburskiJ.\%27\%29 (02/12/2003)

6. Díaz, C.; A. González; Y. Rodríguez. 2002. Efecto del espacio vital sobre los indicadores productivos y de la canal de los cerdos. Disponible: http://www. sian.info.ve/porcinos/publicaciones/ viencuent/diaz.htm (26/04/2002)

7. Humala, A. 1971. Efecto de tres áreas mínimas de corral por animal sobre la velocidad de crecimiento en cuyes $(\mathrm{Ca}$ via porcellus). Tesis de Bachiller. Facultad de Zootecnia, Univ. Nacional Agraria La Molina. Lima.

8. INIAA-CIID. 1990. Sistemas de producción de cuyes en el Perú. p 48-49. Informe Técnico Final (junio 1986 - mayo 1990).

9. Llorente, R.; G. Polanco; R. Quiñones. 1986. Efecto de la densidad de alojamiento en pollos de engorde criados en piso en los meses de invierno. Rev. Avicultura 30: 37-42.

10. Polanco, G.; H. Manso. 1986. Comparación de dos densidades de alojamiento en pollos de engorde criados en piso. Rev. Avicultura 30: 43-48.

11. Quiñones, R.; G. Polanco; R. Llorente. 1986a. Efecto del empleo de altas densidades de alojamiento en la crianza de pollos de engorde en piso. I. Estación de seca. Rev. Avicultura 30: 21-25.

12. Quiñones, R.; G. Polanco; R. Llorente. $1986 b$. Efecto del empleo de altas densidades de alojamiento en la crianza de pollos de engorde en piso. II. Estación de lluvia. Rev. Avicultura 30: 29-33.

13. Snedecor, G.; W. Cochran. 1967. Stathistical Methods. $6^{a}$ ed. p 325. Iowa State University Press. USA. 